\title{
STORYBOARD: uso estratégico da ferramenta no planejamento de revistas
}

\author{
Maria Carolina Frohlich Fillmann \\ Escola Superior de Propaganda e Marketing \\ cfillmann@espm.br
}

\section{RESUMO}

O presente artigo pretende fazer uma reflexão sobre o uso estratégico da ferramenta de design storyboard no planejamento de publicações do tipo revista, dentro de um espaço de atuação multidisciplinar. Para isso, pretende-se compreender o universo no qual é compreendido o storyboard dentro do cinema e da publicidade para, posteriormente, compreender semelhanças e diferenças quando a ferramenta é aplicada ao mundo do design e, mais especificamente, ao design editorial. Nessa perspectiva, analisam-se algumas demandas da rotina do trabalho em equipe em uma redação para entender onde o design pode, de maneira estratégica, contribuir, e o quanto o storyboard pode apresentar-se determinante para isso.

Palavras Chave: storyboard; design editorial; revistas; planejamento editorial. 


\section{INTRODUÇÃO}

Cada vez mais presente entre as disciplinas do design gráfico, o design editorial se caracteriza por ser a área do design que trata especificamente de publicações, ou seja, artefatos de design gráfico que contenham páginas e que trabalhem com grande densidade de texto. Tendo os livros, jornais e revistas como seus principais produtos, por muito tempo o design editorial e seu exercício passaram despercebidos dentro de grandes redações e editoras. Mas com os avanços das tecnologias de desenvolvimento de publicações, principalmente no quesito relacionado aos softwares de construção de páginas e as inovações da indústria gráfica, seu espaço de atuação e reconhecimento passou a ser aumentado. "A tecnologia digital, de fato, aumentou as possibilidades de manipulação das formas e dos recursos gráficos, centralizando nas mãos do designer gráfico uma série de decisões que lhe asseguram uma maior autonomia no desempenho de suas funções", (GRUSZYNSKI, 2007, p. 13).

Ampliou-se não apenas o cuidado com o layout das páginas, como também o pensar estratégico do design sobre a publicação inteira. Como característica do design, o ambiente projetual constitui-se pela complexidade. Este é o caso da construção de um projeto em design editorial, que ocorre por meio de um processo criativo realizado pelo design, com construções específicas dessa área de conhecimento, mas abastecido por outras áreas relacionadas.

Neste tipo de processo, dois pontos importantes devem ser ponderados no momento da projetação: um, o necessário envolvimento e dependência dos profissionais da área de conteúdo, integrados aos profissionais de design; e outro, a possibilidade e intenção de alguma periodicidade que pode ser adquirida por cada publicação projetada.

No que tange ao design editorial, a integração com os profissionais de conteúdo faz com que o designer, na atuação coletiva com esses profissionais, passe a pensar na forma da publicação, no tipo de texto ou matérias que irá conter, o uso que será feito das imagens, a composição da obra e o ritmo de leitura que será dado. Isso porque a "individualidade define valores absolutamente subjetivos sobre elementos que afetam as possibilidades de concretizar um trabalho satisfatório", (FUENTES, 2006, p. 27).

Já a possibilidade de ser uma publicação com periodicidade constante faz com que o projeto ganhe uma temporalidade potencializada, onde a necessidade comercial, seja de patrocínio ou de anúncios, se coloque como de extrema necessidade para a garantia da sustentabilidade do projeto. Para fins deste artigo, sempre que citarmos um projeto editorial estaremos nos referindo a um projeto de revista.

Segundo Celaschi e Desserti (2007), e aqui caracterizando conforme universo editorial, o design passa a ser reconhecido como um recurso estratégico e inovador, de visão sistêmica, que contribui para o planejamento de ações, inclusive junto a outras áreas de uma organização, devido a um conjunto de atividades de análises, diagnósticos, coordenações e negociações que resultam na criação de publicações e serviços diferenciados e adequados às necessidades da editora e do seu público leitor.

De acordo com a visão estratégica do design, a contribuição para toda a empresa é possível porque conta com uma integração de uma equipe multidisciplinar e com fontes de informações do contexto empresarial, recebendo o suporte de estratégias de pesquisa, muitas vezes traduzidas em instrumentos e métodos. "Embora grande parte do conteúdo físico de uma publicação chegue ao designer pronto para iniciar o processo de design, cada vez mais profissionais vêm se envolvendo ativamente no desenvolvimento de conteúdo a partir de uma perspectiva estratégica e editorial", (SAMARA, 2011, p. 20).

Para que o projeto seja, então, devidamente construído, além de questões estéticas tangíveis ao design é preciso a eleição de uma estratégia de ação, que contemple todos os personagens e necessidades envolvidas, principalmente o casamento entre textos e informações comerciais fundamentais a uma 
edição de revista. Tal estratégia pode ser alcançada mediante o uso de instrumentos ou ferramentas do design que devem ser aplicadas com o objetivo de organizar as ideias ao longo do desenvolvimento do projeto e da aplicação do mesmo.

Sendo assim, este artigo se propõe a refletir qual a importância de uma das ferramentas de design aplicadas a construção de publicações: o storyboard. Toma-se aqui o conceito definido por Lins (2004), onde, em sua metodologia de design, passa a tratar o recurso conhecido como espelho pela denominação de storyboard. Isso porque, a planificação de uma publicação em suas páginas duplas, na ordem de leitura, assemelha-se muito ao uso já difundido do storyboard no mercado. Para isso, pretende-se entender o conceito de storyboard nas áreas nas quais essa ferramenta continua sendo a mais utilizada, como o cinema e a publicidade, e também resgatar o conceito dessa ferramenta no universo de aplicação da produção de publicações.

\section{STORYBOARD NO CINEMA, PUBLICIDADE E DESIGN}

A ampliação do papel do design nas editoras e redações modificou igualmente a natureza de seus processos de projeto que, tradicionalmente, compreendem uma série de etapas onde o designer planeja algo que ainda não está constituído com o objetivo de solucionar problemas apresentados pelo briefing. Nesse ponto, cabe ao designer a execução do trabalho que inicia pela compreensão da problemática e das necessidades da publicação e segue com o destaque dos problemas pela análise do briefing, o desenvolvimento de conceitos que poderão auxiliar na construção do projeto, teste de protótipos e, por fim, a revisão do projeto antes do encaminhamento para a produção.

Pensando-se nas etapas de controle e na divisão intensiva do trabalho, a fragmentação dos processos de projeto mostra a necessidade de percebê-lo como um todo. Dessa forma, o design se estabelece como uma parte específica do processo produtivo. Passa a ser visto, então, como uma atividade que opera além da materialização de objetos, envolvendo atividades relacionadas à organização e planejamento de ações. Isso significa que o "designer tem diante de si a tarefa de avaliar a forma editorial do conteúdo para determinar que componentes ou métodos comunicarão de forma mais clara a mensagem, além de estabelecer a ordem segundo a qual esses componentes devem ser seqüenciados", (SAMARA, 2011, p. 20).

Nesse ínterim, planejar um publicação requer cuidados relacionados tanto com sua linha editorial e com sua forma gráfica, como com seu desempenho comercial, distribuição e periodicidade. Levando-se em conta a realidade de uma revista, há a preocupação com o planejamento do projeto, quando ele deve ser lançado ao mercado editorial, e o posterior planejamento de cada uma das edições que devem ser criadas ao longo da existência de uma publicação.

Para a primeira etapa, do planejamento do projeto, um longo e cuidadoso processo de pesquisa é feito para que se crie uma publicação que realmente será diferente das já existentes e que possa conquistar o público leitor em poucas edições. A pesquisa revela os resultados que serão determinantes para que a equipe planeje o tipo de texto que será redigido, as formas que terão as páginas, o tipo de imagem a ser utilizada, o espaço comercial que terá. Ou seja, a pesquisa dá os subsídios necessários para a criação dos projetos editorial, projeto gráfico e projeto comercial.

Isto posto, a publicação, quando devidamente integrada nesses três principais projetos - editorial, gráfico e comercial -, passa a ter sua periodicidade colocada em execução. A dificuldade do momento do projeto inicial se estende para cada uma das edições que devem ser feitas, a fim de manter a qualidade da publicação e a constância de seus assuntos e seu interesse. É neste momento que revela-se a necessidade de aplicação de uma ferramenta, capaz de ponderar e equilibrar os projetos editorial, gráfico e comercial. 
Tal instrumento possui como denominação no campo do design storyboard, mas é conhecido e chamado nas redações e editoras pelo nome de espelho.

Antes mesmo de se conhecer como o storyboard é apropriado como metodologia de projetação e desenvolvimento de publicações pelo design editorial, será feita uma revisão de seus conceitos em suas principais áreas de aplicação, como o cinema e a publicidade, revisando suas características e funções em cada uma dessas áreas.

O uso do storyboard está atrelado ao fato de narrar-se visualmente uma história ou um acontecimento numa sequência lógica, ou seja, compreende uma disposição de elementos visuais que representam uma narrativa no tempo. O storyboard é muito utilizado pela indústria do cinema, onde ele serve como ferramenta de preparação para o filme. São ilustrações exibidas em sequência com a finalidade de pré-visualização. "O storybooard é essencialmente uma grande história em quadrinhos do filme ou de parte dele, produzida com antecedência para ajudar os diretores e cineastas a visualizar as cenas e a encontrar potenciais problemas antes que eles ocorram”, (LESLIE, 2006, p. 159). Ou seja, no mundo do audiovisual o storyboard é uma ferramenta projetada para dar uma programação organizada do plano de filmagem, frame por frame, tomada por tomada. Na maioria das vezes, o seu desenvolvedor, guiado pelo diretor do filme, captura as ações e as passagens traduzíveis do filme.

Fischer, Scaletsky e Amaral (2010) afirmam que o storyboard herda as características das histórias em quadrinhos, comuns em jornais e revistas, mas com maior força que uma $H Q$, transformando-se num elemento de bastidor, de cunho preparatório, objetivando o projeto de um produto de cinema destinado ao público. Mesmo que tenham havido evoluções técnicas na construção dos storyboards, "apresentar uma proposta gráfica que se aproxime ao máximo do que se trata e como se deseja expressar determinada história, segue sendo essencial e ainda resgata a linguagem do desenho e da HQ", (FISCHER, SCALETSKY E AMARAL, 2010, p. 56).

O uso do storyboard pela indústria do cinema não só ajuda ao diretor e ao cinegrafista anteverem as cenas de maior tensão, pelo ângulo mais apropriado, como também é utilizado diante dos possíveis financiadores para convencê-los do investimento. Como afirma Leslie, "não só ajuda o diretor e o cinegrafista a "ver" os tiros antes de eles serem executados, como também ajuda o produtor a convencer potenciais financiadores, busca de locais e até mesmo a começar o lançamento do filme. Além disso, auxilia na construção de cenas, nos efeitos especiais e nos adereços", (LESLIE, 2006, p. 159). Dessa forma, abre possibilidade para que o investidor tenha acesso ao roteiro do filme e, eventualmente, participe de certas discussões e aprovações. O storyboard também pode ser empregado para se pesquisar locais e até mesmo começar o lançamento, projetando entre os membros da equipe aquilo que deverá ser posteriormente filmado ou animado.

Os storyboards também são amplamente utilizados na indústria da publicidade e propaganda. Neste meio, o storyboard desempenha a função de preparar ou projetar uma solução de comunicação, onde filmes serão desenvolvidos para se tornarem peças publicitárias. Nesse contexto, os storyboards são vistos como sendo ilustrações exibidas em sequência, com a finalidade de pré-visualização de um anúncio de comercialização ou promoção de um produto. "Storyboards são uma ajuda valiosa para o designer nesta tarefa, fornecendo uma linguagem visual comum que pessoas de diferentes origens podem "ler" e entender", (LESLIE, 2006, p. 159).

A função maior nesse campo é a de organizar o fluxo de imagens. Dessa forma, acaba compondo uma peça que "sai do bastidor em que a equipe criadora se encontra, para protagonizar o processo de apresentação e discussão diante de outro ator fundamental ao processo publicitário, o cliente", (FISCHER, SCALETSKY E AMARAL, 2010, p. 56). Assim, segundo os autores, o storyboard assume dois papeis 
importantes no campo da publicidade: tanto serve como instrumento de projetação como também se apresenta como peça. Ou seja, pode vir a ser o layout por meio do qual se simulam anúncios para jornais e revistas, além de outras soluções que podem vir a ser submetidas ao cliente para defender a ideia e conceito da campanha criada.

Como tem a função de antecipar as etapas da narrativa visual e todo o desenvolvimento de ações em uma campanha, o storyboard constitui-se como "instrumento com potencial para participar do processo decisório e, com isso, sua preparação e apresentação estão tencionadas por essa possibilidade", (FISCHER, SCALETSKY E AMARAL, 2010, p. 57). Ou seja, o desenvolvedor do storyboard para o discurso publicitário acaba trabalhando através da narrativa visual o caráter persuasivo que a história que será entregue ao cliente e ao consumidor deve ter. Essa ferramenta ajuda a vender a ideia do conceito e a aprovar com o cliente.

Percebe-se, tanto no caso da indústria do cinema, quanto no mundo da publicidade, que o storyboard é utilizado para a pré-visualização de como será o produto final, auxiliando no melhor angulo, melhor corte de cena e também na venda e aprovação do produto que está sendo projetado.

No mundo do design, a apropriação do storyboard não é muito diferente. Ele funciona como "elemento de geração e simulação de ideias e de comunicação com os outros atores envolvidos no processo de projeto", (FISCHER, SCALETSKY E AMARAL, 2010, p. 57). Acaba desempenhando uma importante tarefa da fase de análise do projeto, quando o problema é identificado e depois funcionando como elemento integrador durante a fase de respostas ao projeto. "Storyboards não só ajudam o designer de produto a começar a compreender os grupos-alvo, o contexto de uso do produto e tempo, mas também na comunicação sobre estes aspectos, com todas as pessoas envolvidas", (LESLIE, 2006, p. 159).

Outra função do storyboard no design é a de auxiliar o projetista a compreender como se dá a interação do produto pelo usuário em seu contexto. "Enquanto as indústrias de cinema e publicidade usam storyboards para fornecer uma pré-visualização do filme com fins de produção, o storyboard no design de produto ajuda o designer a compreender a interação do produto pelo usuário no contexto, e ao longo do tempo", (LESLIE, 2006, p. 160).

Também a utilização de storyboards permite aos designers e demais participantes do projeto a perceber "três elementos essenciais em um projeto de design, muitas vezes dificilmente representáveis de forma compreensível: o contexto em que o projeto se insere, a interação entre usuários e esse contexto e o tempo", (FISCHER, SCALETSKY E AMARAL, 2010, p. 58) De acordo com os autores, o storyboard, como ferramenta de compreensão do contexto do projeto pode auxiliar na delimitação do problema e na construção de conhecimento em torno dele. Dessa forma, faz com todos os participantes estejam com as mesmas informações e conhecimento a respeito do contexto em que vão trabalhar, principalmente conectados ao tempo que o projeto deve ter e o tempo em que as ações devem se desenrolar.

\subsection{0 planejamento de uma publicação}

Como visto, uma das principais características do storyboard é a de situar a equipe de trabalho com relação ao contexto do problema e o conhecimento em torno dele. O seu uso, na produção de uma revista, segue o mesmo princípio. Depois dos projetos editorial, gráfico e comercial constituídos, a equipe de trabalho que passará a projetar uma revista, uma edição que deverá ser colocada à venda e distribuída em sua praça de atuação, reúne-se para fazer o que nas redações chama-se de reunião de pauta, o que nada mais é do que a reunião de planejamento da edição.

Nesse momento, expõe-se a necessidade de cada área para o projeto em questão e todos os pontos que deverão se levantados durante a edição. Discute-se tanto a pauta em termos de matérias e suas 
abordagens, como também o trabalho estético que deverá ter cada uma dessas matérias, a fim de encantar o leitor, e as possibilidades de anúncios e anunciantes da edição em questão. “O designer deve levar em conta as necessidades potenciais de um conteúdo que ele ainda não viu para certificar-se de que ele possa ser adaptado às ideias de composição desenvolvidas", (SAMARA, 2011, p. 64).

Reunião de pauta concluída, número de páginas da edição definido, a primeira ação que deve seguir as decisões iniciais é a elaboração do storyboard, comumente chamado na redações de boneco. "Munidos de dados técnicos (formato, número de páginas, cores possíveis, etc.) fornecidos pelo cliente, ele começa a separar o texto em páginas... esta planificação inicial é geralmente feita como se fosse um storyboard ou posicionando-se as páginas duplas em ordem de leitura", (LINS, 2004, p. 56). De maneira semelhante aos conceitos anteriormente levantados, a sua função é a de posicionar as páginas da edição, em duplas, para que toda a equipe de trabalho passe a ter a mesma visão, o mesmo conhecimento dessa edição.

Um primeiro storyboard é gerado em cima das previsões. Isso porque, como Schön (2000) se refere, há uma reflexão na ação durante todo o desenvolvimento da edição. Isso quer dizer que o storyboard será revisitado, reajustado e refeito quantas vezes forem necessárias até estar em conformidade com a realidade final da publicação. "As publicações seriadas devem ser desenvolvidas como sistemas para acomodar as mudanças de conteúdo: cada edição é um objeto único, mas a lógica visual da publicação precisa ser consistentemente reconhecível a seus leitores, embora flexível o suficiente para permitir mudanças de conteúdo", (SAMARA, 2011, p. 64).

O primeiro ponto essencial a ser abordado é a demanda comercial. Por uma questão de sustentabilidade de cada edição, tem-se como prática mediana de mercado o uso de vinte por cento do número de páginas total da publicação destinado a anúncios. Esses anúncios podem ser de página dupla, página inteira simples, meia página, rodapé ou de um terço vertical. Essa situação acaba interferindo diretamente em como as páginas e pautas serão dispostas, e como se dará o design gráfico de cada matéria.

Os anúncios passam, então, a serem distribuídos pelas páginas. Dessa forma, o storyboard estará com seus espaços comerciais completados. De acordo com a previsão do espaço comercial, o segundo ponto é a disposição das matérias que correspondem a seções fixas da publicação. "Publicações editoriais... organizam seu conteúdo como artigos ou matérias, com o suporte de imagem que são, em geral, documentais. As matérias tendem a ser agrupadas por categorias", (SAMARA, 2011, p. 20).

Muitas revistas, como é o exemplo da revista Veja e sua entrevista de páginas amarelas, tem seções tradicionais, localizadas sempre no mesmo tempo da revista. Seções fixas determinadas, passa-se a distribuição das demais matérias previstas para a edição. “Em geral, há duas grandes partes... A parte de seções fixas traz páginas dedicadas ao mesmo tipo de informação a cada edição... Já as matérias são maiores e exploram em maior profundidade o assunto da revista", (idem, p. 20).

No momento de confecção do storyboard, muitas pautas passam a ser revistas em seu tamanho, já que para o encaixe de tudo o que é necessário na edição, muitas vezes algumas matérias terão número de páginas diminuídos ou aumentados. É possível, também, que certas pautas sejam dispensadas ou até mesmo acrescentadas. É nesse momento que o desenho do storyboard acaba determinando discussões entre a equipe de trabalho para que se pondere como a redação irá trabalhar determinadas matérias.

Quando um primeiro storyboard é considerado definitivo, seus frames - páginas - acompanharão as equipes de redação, comercial e de design para o desempenho do trabalho. À medida que as matérias vão sendo apuradas, ocorre a conversa entre redação e equipe de design para que as matérias possam ser projetadas em seu layout, de acordo com o número de páginas que deverão assumir na edição. 
O storyboard pode ser gerado tanto de forma analógica, desenhado a mão, como através de softwares digitais. Essa ferramenta permite a visualização das páginas da revista em cada fase, desde da criação, edição, alteração, até o seu envio à gráfica. O seu uso traz ganhos ao processo produtivo. A sua adoção antecipa a união do conteúdo editorial com o de publicidade durante o desenvolvimento da edição, quando nos primórdios das publicações acontecia apenas no momento da gráfica. Com ele é possível ter o controle das diferentes versões de layout das páginas. Também o controle do cronograma de produção passa a ser acompanhado pelo storyboard, pois à medida que as matérias ficam prontas em layout e edição elas são sinalizadas no storyboard que circula entre as equipes.

Um exemplo de storyboard inicial de revista pode ser visto abaixo:

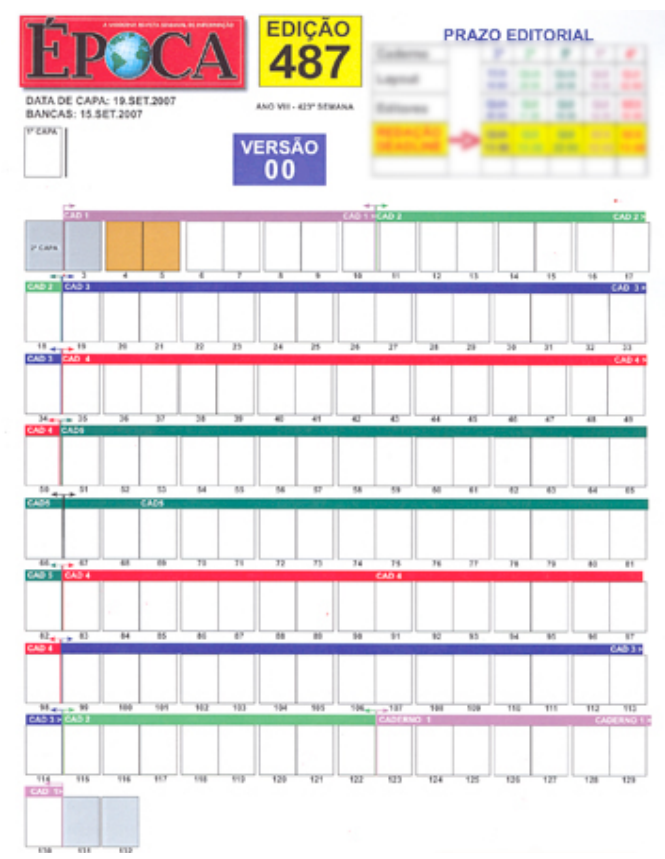

Figura 1 - versão inicial, para início das tratativas, da revista época. Fonte: http://colunas.epoca.globo.com/fazcaber/files/2008/09/espelho.jpg

Outro exemplo de storyboard de publicação pode ser conferido abaixo:

Layout of story in a magazine

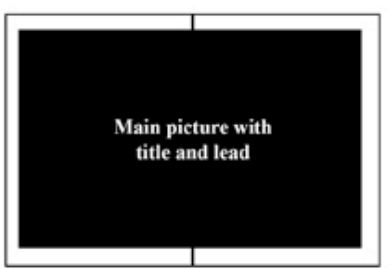

Spread 1

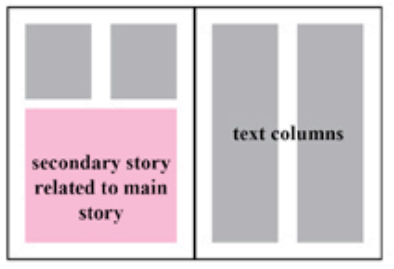

Spread 3

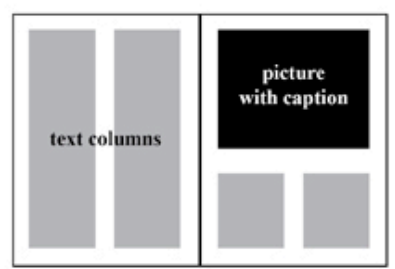

Spread 2

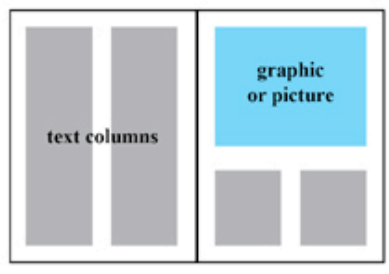

Spread 4 
Figura 2. Fonte: http://www.niemanstoryboard.org/2011/09/08/story-interrupted-why-we-need-newapproaches-to-digital-narrative/

Para a equipe de design, o uso do storyboard tem a importância de fazer prever o layout das páginas. Sabendo a distribuição que as matérias tomarão ao longo do corpo da revista, é possível fazer uma previsão do uso das cores, elementos visuais e dinâmica das matérias. Quanto as cores, no design editorial é importante prever, de acordo com o projeto da publicação, como será feita a sua distribuição. "A cor, assim como o texto e a imagem, de fato configura conteúdo, e deve ser discutida durante o processo de design de uma publicação", (SAMARA, 2011, p. 26).

Seções fixas podem ter suas cores padronizadas pela paleta de cores definida no momento da definição do projeto. Já as matérias complementares, poderão ter suas cores alternadas de acordo com a disposição com que serão colocadas na revista. Por meio do storyboard a equipe de design tem o controle de não repetir tonalidades próximas e alternar as cores para levar dinamicidade à leitura. "A codificação por cores - atribuir cores para identificar seções ou componentes - é uma forma de usar a cor como sistema. Para ser eficaz, a codificação por cores deve ser simples e facilmente identificável", (idem, p. 29).

Da mesma forma que o storyboard auxilia na distribuição de cores, também trabalha com as imagens. Há um cuidado para que as matérias que se utilizem de infográficos, por exemplo, não fiquem todas juntas, se alternando com as matérias que se utilizam apenas de imagens. Também, as páginas de artigo possam ser distribuídas ao longo da revista a fim de que se alterne páginas com mais elementos visuais com outras de menos elementos.

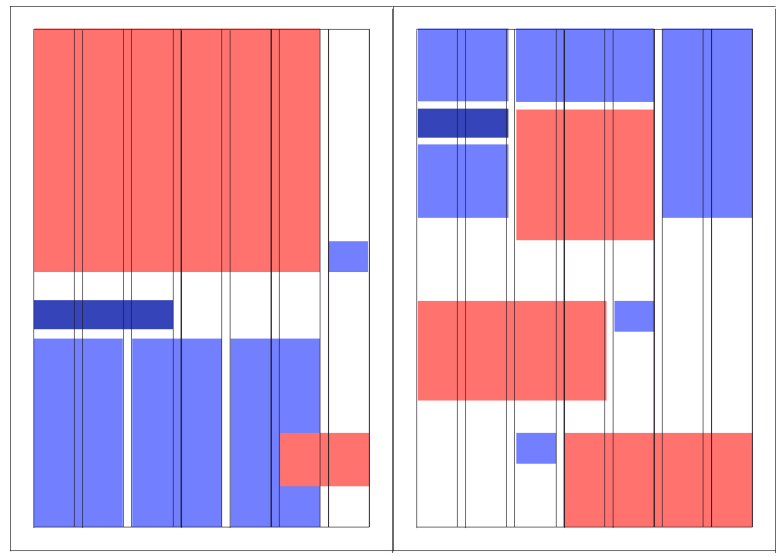

Figura 3 - exemplo de estudo de disposição dos elementos. Fonte: http://raifceyhunsahin.wordpress.com/2010/04/02/new-grid-system-for-my-magazine-design/

Essas preocupações se representam na composição da publicação, para que seu conjunto de páginas se apresente ao leitor com equilíbrio e ritmo de leitura. Muitas vezes, durante o projeto de layout de cada matéria, a equipe de design torna a conversar com a equipe de redação, podendo prever maneiras diferentes de dispor a estética de cada matéria ou até mesmo mudando de lugar as matérias ao longo da revista de acordo com sua estética.

Outra preocupação, de ordem mais técnica, pode ser prevista através do storyboard. Com esse instrumento é possível prever o número de cadernos que terá a publicação e o tipo de lombada e acabamento da revista. Com a visão dos cadernos, é possível rever a colocação dos anúncios, visando antecipar alguma definição de cor, já que a calibragem de cor acontece por cadernos de impressão. A cada 
página, também é checada se a resolução de todas as imagens é adequada, se esta possui sangria e marcas de corte devidamente ajustadas e também, se a quantidade de tinta CMYK em cada ponto da página está de acordo com o nível permitido pela gráfica, para que este anúncio não tenha problemas ao ser impresso.

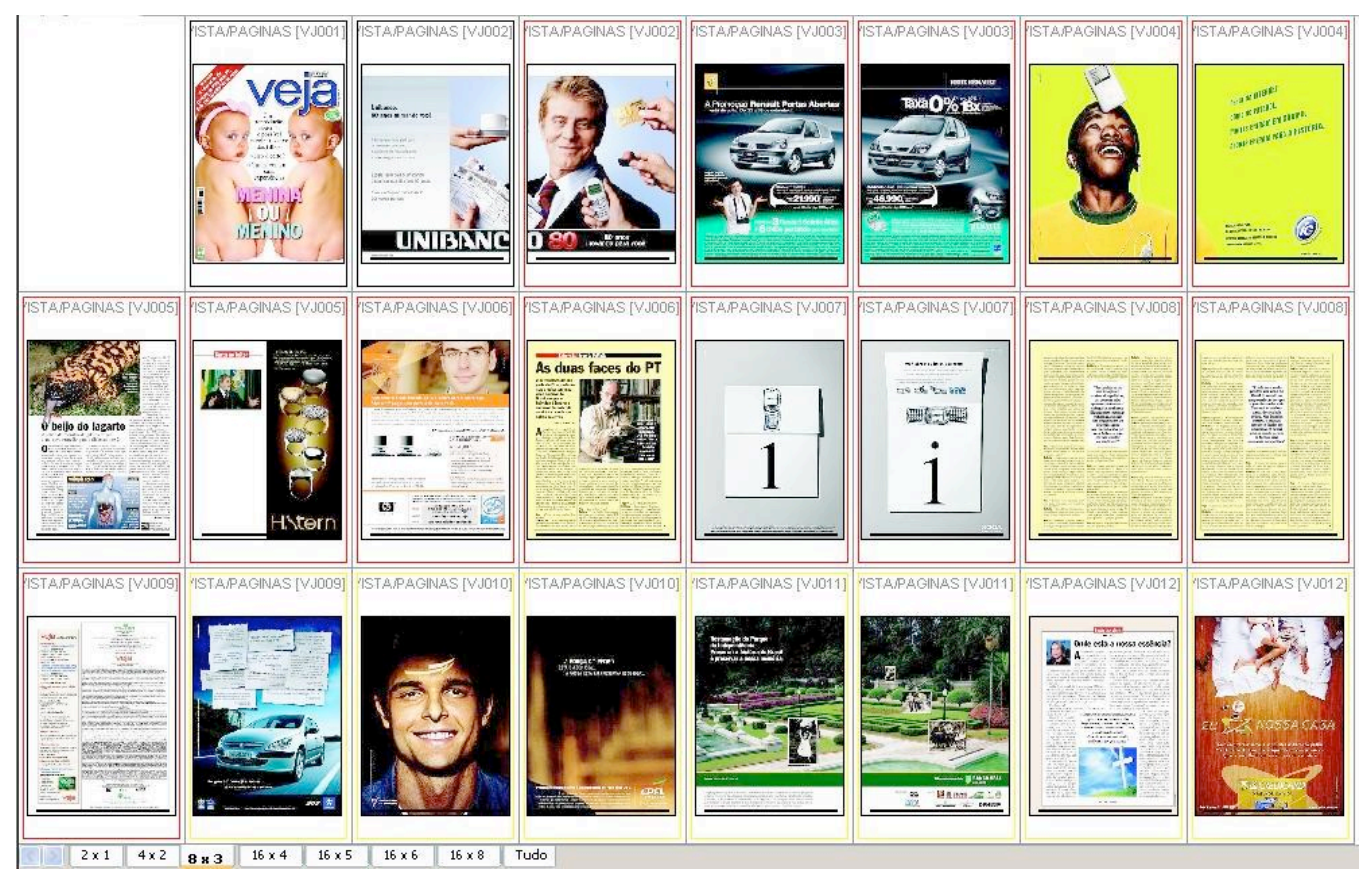

Figura 4 - exemplo storyboard acessível a todas as equipes de trabalho, já com a distribuição de cadernos de impressão da revista. Fonte: http://www.linux.ime.usp.br/ cef/mac49904/monografias/tkaneto/abrilEspelho.htm

Essas práticas de execução da revista demonstram que no momento de geração e troca de ideias entre as diferentes equipes responsáveis pela execução de uma publicação, o storyboard se associa a construção de modelos que antecipam situações do projeto. Dessa forma, apresenta-se para a equipe de trabalho uma maneira simplificada de como ficará a publicação na realidade, permitindo que se avalie a pertinência ou não de determinadas decisões tomadas em equipe.

O storyboard de uma publicação, na sua denominação espelho, constrói em forma de uma narrativa a representação temática das matérias e assuntos de uma revista. Com essa ferramenta, é possível dimensionar os tempos de leitura e as possíveis emoções dos leitores diante de cada texto que será lido, tornando-se um instrumento essencial para a construção do projeto de uma edição de publicação. Através do storyboard, é possível trabalhar e dimensionar a expectativa do leitor diante da significação que cada página possa traduzir.

A ferramenta funciona, então, como um instrumento de bastidor, que comunica e simula de maneira compreensível e didática entre toda a equipe de trabalho as ações, experiências, procedimentos de execução do projeto. Ou seja, o storyboard "proporcionam uma linguagem visual comum que apoia as pessoas de diferentes origens para se comunicar sobre aspectos do design. Clientes, membros da equipe de projeto, especialistas e usuários futuros podem "ler" um storyboard", (LESLIE, 2006, p. 160).

\section{CONCLUSÃO}


O pensar estratégico do design cada vez mais ganha espaço no momento da projetação. É a aplicação do design como um recurso estratégico e inovador, que contribui para o planejamento de ações integrando diferentes áreas da organização. Essa estratégica se aplica também na projetação de soluções do design editorial para a construção de publicações.

Para esse pensar estratégico o design adere ao uso de ferramentas no momento da projetação. No que tange ao design editorial, amplia-se não apenas o cuidado com o layout das páginas, como também o pensar estratégico do design sobre a publicação inteira. Esse pensar, irá permear a decisão das diversas equipes de trabalho de uma redação, balizando as decisões de cada área.

Entre as ferramentas do design, destaca-se o storyboard. Inicialmente utilizado pelas áreas de cinema e publicidade, o storyboard se destina a ser uma ferramenta que narra em uma sequência de imagens a previsão do projeto a ser desenvolvido. Também funciona como um instrumento de diálogo da equipe, além de ponderar aprovações e potencializar a venda e o financiamento das obras.

No design editorial, o storyboard, onde é mais conhecido pela denominação "espelho", faz as vezes de instrumento de comunicação entre as equipes de trabalho. Com a previsão da publicação através das páginas duplas, prevê a distribuição de anúncios, a distribuição de matérias e o equilíbrio de cores, imagens e focos visuais.

\begin{abstract}
Um espelho ou diagrama de paginação de uma revista, é uma ferramenta inestimável para o designer. A possibilidade de visualizar a sequência completa de páginas e cadernos ajuda a planejar onde o conteúdo pode ser unido, e permite prever o efeito que adições, deleções ou reposicionamentos de conteúdo entre páginas duplas terão sobre o número de páginas e fluxo de leitura. (SAMARA, 2011, p. 66).
\end{abstract}

Com seu uso constante no dialogo entre as diferentes equipes de trabalho em uma redação, o storyboard apresenta-se como uma ferramenta de design de cunho altamente estratégico para o planejamento de uma revista. É em cima da sequência de páginas e seu layout apresentado que serão tomadas decisões de posicionamento editorial e comercial, que são determinantes para a sustentabilidade de uma publicação.

Indispensável para todas as equipes, é uma arma essencial ao designer, que nas publicações seriadas devem levar em conta uma série de variáveis além dos aspectos básicos da composição estética. Muitos dos problemas hierárquicos de diversas páginas duplas em sucessivas edições são resolvidos por meio do trabalho contínuo com a ferramenta do storyboard. Assim, empregado de maneira relativamente diferente do cinema e da publicidade, onde tem sua origem, o storyboard mostra-se também estratégico para o campo de atuação do design editorial.

\title{
REFERÊNCIAS
}

CARDOSO, Rafael (Org.). Uma introdução à história do design. São Paulo: Edgard Blücher, 2005

CELASCHI, Flaviano e DESERTI, Alessandro. Design e Innovazione - Strumnti e pratiche per la ricerca applicata. Milão: Carocci, 2007.

FISCHER, GUSTAVO; SCALETSKY, CELSO CARNOS; E AMARAL, LAURA GUIDALI. O storyboard como instrumento de projeto: reencontrando as contribuições do audiovisual e da publicidade e seus contextos de uso no design. Strategic Design Research Journal, 3(2): 54-68 maio-agosto 2010 
FUENTES, Rodolfo. A prática do design gráfico: uma metodologia criativa. Tradução Osvaldo Antonio Rosiano. São Paulo: Edições Rosari, 2006. Coleção fundamentos do design.

GRUSZYNSKI, Ana Cláudia. A imagem da palavra: retórica tipográfica na pós-modernidade. Teresópolis, Rio de Janeiro: Novas Idéias, 2007.

LELIE, C. van der. 2006. The value of storyboards in the product design process. Persona land Ubiquitous Computing, 10 (2-3):159-162. Disponível em: http://www.springerlink.com/content/Imvm49832p4887r1/. Acesso em: 01/09/2008.

LINS, Guto. Livro infantil? Projeto gráfico, metodologia, subjetividade. São Paulo: edições Rosari. 2004, 2ạ edição.

MCQUAID, H.M.; GOEL, A.; MCMANUS, M. 2003. When you can't talk to customers: Using storyboards and narratives to elicit empathy for users. In: DESIGNING PLEASURABLE PRODUCTS AND INTERFACES CONFERENCE, Pittsburgh, 2003. Anais... Pittsburgh. Disponível em: http://portal.acm.org/citation.cfm?id=782 926. Acesso em: 01/09/2008

SAMARA, Timothy. Guia de design editorial. Manual prático para o design de publicações. Porto Alegre: Bookman, 2011.

SCHÖN, Donald A. Educando o Profissional Reflexivo. Porto Alegre: Artmed, 2000. 